\title{
Prevalence of Rotavirus and Adenovirus in the Childhood Gastroenteritis in a Tertiary Care Teaching Hospital
}

\author{
Arvind N. ${ }^{1 *}$, Sushma M. ${ }^{2}$ and Krishnappa J. ${ }^{3}$ \\ ${ }^{1}$ Department of Microbiology, Sri Devaraj Urs Medical College, Tamaka, Kolar, Karnataka, India. ${ }^{2}$ Sri Devaraj Urs \\ Medical College, Tamaka, Kolar, Karnataka, India. ${ }^{3}$ Department of Paediatrics, Sri Devaraj Urs Medical College, \\ Tamaka, Kolar, Karnataka, India.
}

\begin{abstract}
Gastroenteritis in the childhood is one of the most common cause of morbidity and mortality throughout the world. Acute gastroenteritis is caused by bacteria, viruses, parasites, and rarely fungi. The cases of viral gastroenteritis are gradually increasing resulting in a global problem among children. This warrants the need of local, regional and national epidemiological data on the most common agents causing childhood gastroenteritis for clinicians for treatment protocol, Public health officials to implement control measures and for Researchers to develop suitable vaccines. The present study was conducted to determine the prevalence of Rotavirus and adenovirus in the childhood gastroenteritis and its epidemiological importance in a tertiary care teaching hospital. Children below 14 years of age attending a rural tertiary care hospital with diarrhea, vomiting and fever of less than $\mathbf{3}$ days were included in our study. The sample size was 38. General physical examination, clinical findings and other epidemiological data were also recorded. A commercial Rotavirus and Adenovirus antigen detection kit was used to detect the presence of Rotavirus and Adenovirus antigen from the stool sample. Out of 38 children screened, 11 children (28.94\%) were positive for Rotavirus, 1 ( $2.63 \%$ ) child was positive for Adenovirus and 26 (68.42\%) children were negative for both Adenovirus and Rotavirus. The positivity rate of rotavirus in children aged less than 5 years was of $54.4 \%$. Diarrhoea, fever and vomiting were the commonest symptoms seen in Rotavirus positive children. There is no single gold standard test to discriminate the viral gastroenteritis from other agents of gastroenteritis. A simple, rapid immunochromatography test is useful cost effective aid in the developing countries to detect and screen Adenovirus and Rotavirus.
\end{abstract}

Keywords: Acute gastroenteritis, rota virus, adenovirus.

*Correspondence: Dr Arvind Natarajan, drlotus147@yahoo.co.in; 7406614777

(Received: 20 February 2019; accepted: 25 April 2019)

Citation: Arvind N., Sushma M. and Krishnappa J., Prevalence of Rotavirus and Adenovirus in the Childhood Gastroenteritis in a Tertiary Care Teaching Hospital, J Pure Appl Microbiol., 2019; 13(2): 1011-1015. doi: 10.22207/JPAM.13.2.38

(c) The Author(s) 2019. Open Access. This article is distributed under the terms of the Creative Commons Attribution 4.0 International License which permits unrestricted use, sharing, distribution, and reproduction in any medium, provided you give appropriate credit to the original author(s) and the source, provide a link to the Creative Commons license, and indicate if changes were made. 


\section{INTRODUCTION}

Gastroenteritis in the childhood is one of the most common cause of morbidity and mortality throughout the world ${ }^{1}$. World Health Organization (WHO) reports that there are 2 billion cases of acute gastroenteritis every year worldwide ${ }^{2}$. The global burden of acute gastroenteritis is very high, especially in developing countries and India accounts for 3.86 lakhs childhood deaths every year ${ }^{3}$.

Acute gastroenteritis is caused by bacteria, viruses, parasites, and rarely fungi. The viruses causing gastroenteritis in humans include rotaviruses, adenoviruses, caliciviruses, norwalk viruses and astroviruses ${ }^{4}$. The accurate diagnosis of viral gastroenteritis is essential, though it will not influence any initiation of specific antiviral agents it will definitely reduce the unnecessary use of antimicrobials ${ }^{5}$. In developing countries like India, there are limited number of studies done on viral gastroenteritis when compared to bacterial gastroenteritis. This could be mainly credited for failure in viral identification \& scarcity of viral diagnostic facilities in the developing countries ${ }^{6}$.

Rotavirus is the most common etiological agent among viruses causing childhood gastroenteritis. Rota virus is responsible for around 2 million healthcare admissions and 450,000 deaths among childhood gastroenteritis annually ${ }^{7,8}$. Adenovirus has been evidenced as second most common cause of childhood gastroenteritis after Rotavirus in certain parts of the world ${ }^{9}$. There are several studies done on Rotavirus, but enteric adenoviruses are less analyzed.

This warrants the need of local, regional and national epidemiological data on the most common agents causing childhood gastro-enteritis for clinicians for treatment protocol, Public health

Table 1. Number of Rotavirus and Adenovirus cases

\begin{tabular}{lc}
\hline Test result & $\begin{array}{c}\text { Number } \\
\text { ( } \% \text { age ) }\end{array}$ \\
\hline Rota virus positive & $11(28.94 \%)$ \\
Adenovirus Positive & $1(2.63 \%)$ \\
Negative for either & $26(68.42 \%)$ \\
Adenovirus and & \\
Rotavirus &
\end{tabular}

officials to implement control measures and for Researchers to develop suitable vaccines.

The present study was conducted to determine the prevalence of Rotavirus and adenovirus in the childhood gastroenteritis and its epidemiological importance in a tertiary care teaching hospital in Karnataka.

\section{METHODOLOGY Setting}

Department of Pediatrics : Out patients / In patients and Microbiology laboratory, R L Jalappa Hospital and Research Centre

\section{Study period}

June 2018

Study was conducted from July 2017 to

\section{Inclusion criteria}

Children below 14 years of age attending a rural tertiary care teaching hospital with vomiting, diarrhoea of less than 3 days were included in our study. Both out-patients and in patients were included in the study.

\section{Exclusion criteria}

Faeces of children showing the presence of blood and mucus (dysentery) were excluded from the study.

General physical examination and other details like socioeconomic status, personal hygiene, immunization history and growth milestones were also recorded. A well-structured proforma which includes child's name, age, gender, hospital number, Father / Mother's name, and address, any history of illness such as fever, loose stools, vomiting, previous history of diarrhea, growth milestones, dehydration signs were also recorded.

After consent, single faecal sample around $10-20 \mathrm{ml}$ was collected from each child fulfilling the inclusion criteria on reporting to

Table 2. The clinical parameters of children with Rota viral and Adenoviral diarrhea

\begin{tabular}{lccc}
\hline $\begin{array}{l}\text { Clinical } \\
\text { parameters }\end{array}$ & $\begin{array}{c}\text { Rota } \\
\text { virus } \\
\text { positive }\end{array}$ & $\begin{array}{c}\text { Adeno } \\
\text { virus } \\
\text { positive }\end{array}$ & $\begin{array}{c}\text { Negative for } \\
\text { either Adenovirus } \\
\text { and Rotavirus }\end{array}$ \\
\hline Fever & 6 & - & 11 \\
Vomiting & 3 & - & 7 \\
Diarrhoea & 11 & 1 & 26 \\
Dehydration & 6 & 1 & 7
\end{tabular}


Table 3. Age distribution of children infected with Rotavirus / Adenovirus

\begin{tabular}{lcc}
\hline \multicolumn{1}{c}{ Age } & $\begin{array}{c}\text { Number (\%) } \\
\text { of children } \\
\text { infected with } \\
\text { Rotavirus (\%) }\end{array}$ & $\begin{array}{c}\text { Number (\%) } \\
\text { of children } \\
\text { infected with } \\
\text { Adenovirus (\%) }\end{array}$ \\
\hline $0-6$ months & - & 1 \\
$7-12$ months & - & - \\
$1-2$ years & 4 & - \\
$3-5$ years & 2 & - \\
$6-8$ years & 3 & - \\
$9-10$ years & 1 & - \\
$11-12$ years & 1 & - \\
$12-14$ years & - & - \\
\hline
\end{tabular}

hospital. Rectal swabs were discouraged. The relevant clinical data was entered in the proforma A commercial Rotavirus and Adenovirus antigen detection kit (SD Bioline Rota/Adeno Rapid Test kit, Standard Diagnostics, Korea) were used to detect the evidence of Rotavirus and Adenovirus antigen from the feces sample ${ }^{10}$.

The sensitivity of the kit for Rota virus and Adenovirus detection were $99.3 \%$ and $97 \%$ respectively. The specificity of the kit for Rota virus and Adenovirus detection were $99.5 \%$ and $100 \%$ respectively.

The RotaAdeno immuno-chromatographic test is a rapid test that concurrently detects rotavirus and adenovirus in stool samples. $1 \mathrm{ml}$ of diluent was added to the tube containing stool sample, mixed and further 4-5 drops of this mixed suspension was added to the sample port of the cassette and results were interpretated after 20 minutes.

\section{RESULTS}

During the study period, a total of 38 children were enrolled in our study. Of these, $18(47.36 \%)$ were males and 20 (52.63 \%) were females.

\section{DISCUSSION}

Gastroenteritis in the childhood is one of the most common cause of morbidity and mortality throughout the world. Rotavirus and adenovirus as emerged as common etiologies of childhood gastroenteritis. The prevalence of rotavirus gastroenteritis is highly variable depending on the seasons, climatic changes and cases increase is mostly observed during winter ${ }^{11}$.

There are few studies in India who reported the prevalence of Rota virus from children which varied from $14.6 \%$ to $89.9 \%$, although the age groups were not homogenous in these studies $^{12,13,14}$. The high prevalence of Rotavirus diarrhea was attributed to high rainfall, inadequate water supply and improper sewage disposal system $^{15,16}$. In our study Rotavirus infection was detected in $28.94 \%$ of acute gastroenteritis cases which is concurrent with other studies.

In our study, adenovirus was detected in $2.63 \%$ of cases of acute gastroenteritis. Our findings are consistent to the rates reported by Wilhelmi et al who reported adeno virus positivity of $2-31 \%$ in developing countries ${ }^{17}$.

The gastroenteritis due to adenovirus was prevalent throughout the year, with no change based on the seasonal pattern among children. The co-existence of more than one viral agents are not uncommon in gastroenteritis cases. Few studies have observed that co infection varied from $1.3 \%$ to $8 \%^{18}$. In our study we didn't observe any co-infection of Rota virus \& Adeno virus.

Viral gastroenteritis positivity rates varies in different areas, regions and countries due to the variations in the diagnostic methods and different age groups in tested populations.

Rota viral gastroenteritis is considered to be more critical when compared to the other agents causing gastroenteritis. The clinical spectrum of rotavirus gastroenteritis ranges from a self-limiting condition to watery diarrhea, vomiting, fever and sometimes can cause severe dehydration resulting in hospitalization ${ }^{19}$.

Diarrhea, vomiting and fever are the most common clinical presentation.

Few studies suggests that high fever and dehydration are less frequently encountered in Adenovirus when compared with Rotavirus but duration of infection is longer ${ }^{20}$.

Majority of the children experience rotavirus infection at the age of less than five years, but can be evident in every age groups.

Maternal antibodies usually protects infants from pathogens for the first 6 months. Our study showed the rate of rotavirus positivity of $54.4 \%$ in children aged less than 5 years which 
is concurrent with other studies ${ }^{21,22}$.

In the present study, the positivity rate of rotavirus among children aged less than 14 months was $28.94 \%$. This observation is consistent with similar studies who reported the positivity for Turkey with $21 \%$ and South Korea with $25 \%$ but a study done in northern Iran reported higher positivity rate of $62 \%^{23,24,25}$.

Most of the diagnostic services circumvent conducting viral detection tests in gastroenteritis cases because the tests are costlier and also due to lack of testing protocol for viral diagnostic procedures for gastroenteritis. Viral gastroenteritis is generally diagnosed by excluding the bacterial agents according to the clinical picture or the results of the conventional tests ${ }^{26}$.

The conventional tests includes ELISA, Latex agglutination and PCR which provides rapid diagnosis for acute gastroenteritis cases. There are certain advantages of Rapid antigen detection tests as they shows no interference, no cross-reactivity, good reproducibility, and an acceptable concurrence rate with the ELISA, RT$\mathrm{PCR}$, detection techniques ${ }^{27}$.

Therefore, rapid antigen tests could be helpful in clinical settings for the rapid detection of rotavirus and adenovirus in stool samples.

\section{CONCLUSION}

There is no single gold standard test to discriminate the viral gastroenteritis from other agents of gastroenteritis. A simple, rapid immunochromatography test is useful cost effective aid in the developing countries to detect and screen Adenovirus and Rotavirus. Many multicentric studies with larger sample size are essential to detect the rotavirus and adenovirus positive rates and also to formulate the safe preventive \& control strategy policies in our country.

\section{ACKNOWLEDGMENTS}

We would like to thank the Central Diagnostic Laboratory Services and the Paediatric department for their help \& contribution in performing the tests $\&$ the recruitment of cases respectively.

\section{CONFLICT OF INTEREST}

The authors declare that there is no conflicts of interest.

\section{AUTHORS' CONTRIBUTION}

AN design the study. AN and SM collected and process samples and data. AN analyzed the data. AN and JK reviewed intellectual contents. JK collected clinical profile of patients and reviewed manuscript.

\section{FUNDING}

funding.

This study was supported by SDUAHER

\section{DATA AVAILABILITY}

All datasets generated or analyzed during this study are included in the manuscript.

\section{ETHICS STATEMENT}

This study was approved by the Institutional Ethics Committee of Sri Devaraj Urs Medical College, Tamaka, Kolar. Approval number: DMC/KLR/IEC/154/2018-19.

\section{REFERENCES}

1. Liu L., Qian Y., Zhang Y, Zhao L., Jia L. and Dong H. Epidemiological aspects of rotavirus and adenovirus in hospitalized children with diarrhea: a 5-year survey in Beijing. BMC Infectious Diseases, 2016; 16: 508- 514 World Health Organization. Media Centre. Diarrheal disease. [Internet]. 2013. Available from: http://www. who.int/mediacentre/ factsheets/fs330/en/index. html [Last cited on 2013 Aug 22].

3. Purwar S., Bhattacharya D., Metgud S.C., Kumar D., Chitambar S.D., Roy S.A. cross-sectional study on aetiology of diarrhoeal disease, India. Indian J. Med. Microbiol., 2016; 34: 375-9

4. Dey R.S., Ghosh S., Chawla-Sarkar M., Panchalingam S., Natro J.P., Sur D., et al. Circulation of a novel pattern of infections by enteric adenovirus serotype 41 among children below fi ve years of age in Kolkata, India. J. Clin. Microbiol., 2011;49: 500-5.

5. Akan H., zb|rak G., G rol Y., Sarkaya S., Gunduz T.S., Y\|maz G. et al. Rotavirus and adenovirus frequency among patients with acute gastro-enteritis and their relationship to clinical parameters: a retrospective study in Turkey. Asia Pac. Fam. Med., 2009 Nov 29; 8(1): 8.

6. Uchida R., Pandey B.D., Sherchand J.B., Ahmed K., Yokoo M., Nakagomi T., et al. Molecular epidemiology of rotavirus diarrhea among children and adults in Nepal: detection of $\mathrm{G} 12$ strains with $\mathrm{P}[6]$ or $\mathrm{P}[8]$ and a G11P[25] strain. J. Clin. Microbiol., 2006; 44(10): 
3499-505.

7. Wang H., Liddell C.A., Coates M.M., Mooney M.D. Levitz C.E., Schumacher A.E., Apfel H., lannarone M., Phillips B., Lofgren K.T., et al. Global, regional, and national levels of neonatal, infant, and under-5 mortality during 1990-2013: a systematic analysis for the Global Burden of Disease Study 2013. Lancet (London, England), 2014; 384(9947): 957-79.

8. Liu L., Oza S., Hogan D., Perin J., Rudan I., Lawn J.E., Cousens S., Mathers C., Black R.E. Global, regional, and national causes of child mortality in 2000-13, with projections to inform post-2015 priorities: an updated systematic analysis. Lancet (London, England), 2015; 385(9966): 430-40.

9. Ozsari T., Bora G., Kaya B., and Yakut K3. The Prevalence of Rotavirus and Adenovirus in the Childhood Gastroenteritis. Jundishapur J. Microbiol., 2016; 9(6): e34867.

10. Shetty A.K., Kalekhan F.M., Muthiravalapil S.J., Boloor R., Antony B. Detection of Rotavirus and Adenovirus diarrhea in children below five years, in Dakshina Kannada District, a coastal region of Karnataka State, India. Muller J. Med. Sci. Res., 2014; 5: 143-8

11. Motamedifar M., Elham Amini E. and Shiraz P.E. Frequency of Rotavirus and Adenovirus Gastroenteritis Among Children in Shiraz, Iran. Iran Red. Crescent Med. J., 2013; 15(8): 729-733.

12. Bhat P., Macaden R., Unnykrishnnan P., Rao H.G. Rotavirus and bacterial enteropathogens in acute diarrhea of young children in Bangalore. Indian J. Med. Res., 1985; 82: 105-9.

13. Sen D., Saha M.R., Nair G.B., Das P., Niyogi S.K., De S.P., et al. Etiological studies on hospital in-patients with acute diarrhea in Calcutta. Trans. R. Soc. Trop. Med. Hyg., 1983; 77: 212-4.

14. Banerjee I., Ramani S., Primrose B., Moses P., IturrizaGomara M., Gray J.J., et al. Comparative study of the epidemiology of Rotavirus in children from a community-based birth cohort and a hospital in South India. J. Clin. Microbiol., 2006; 44: 2468-74.

15. Paniker C.K., Mathew S., Marhan M. Rotavirus and acute diarrheal disease in children in a Southern Indian coastal town. Bull. World Health Organ., 1982; 60: 123-7.

16. Sengupta P.G., Sen D., Saha M.R., Niyogi S., Deb B.C., Pal S.C., et al. An epidemic of rotavirus diarrhea in Manipur, India. Trans. R. Soc. Trop. Med. Hyg., 1981; 75: 521

17. Wilhelmi I., Roman E., Sanchez-Fauquier A. Viruses causing gastroenteritis. Clin Microbiol Infect., 2003;
9(4): 247-62.

18. Akan H., Izbirak G., Gurol Y., Sarikaya S., Gunduz T.S., Yilmaz G., et al. Rotavirus and adenovirus frequency among patients with acute gastro-enteritis and their relationship to clinical parameters: a retrospectivestudy in Turkey. Asia Pac. Fam. Med., 2009; 8(1): 8.

19. Umesh D., Parashar U.D., Nelson E.A.S., Kang G. Diagnosis, management, and prevention of rotavirus gastroenteritis in children. BMJ, 2013; 347: 77204.

20. GI M., Garipardin M., [ragil P., Aral M., Karabiber H, G ler .Comparison of rota virus and adenovirus type 40-41 in 0-5 yrs children with acute gastroenteritis ANKEM Dergisi., 2005; 19(2): 64-67

21. Tran A., Talmud D., Lejeune B., Jovenin N., Renois F, Payan $C$, et al. Prevalence of rotavirus, adenovirus, norovirus, and astrovirus infections and coinfections among hospitalized children in northern France. J. Clin. Microbiol., 2010; 48(5): 1943-6.

22. Jin Y., Cheng W.X., Yang X.M., Jin M., Zhang Q., Xu Z.Q., Yu J.M., Zhu L., Yang S.H., Liu N., et al. Viral agents associated with acute gastroenteritis in children hospitalized with diarrhea in Lanzhou, China. J. Clin. Virol., 2009; 44(3): 238-41.

23. Topkaya A.E., Aksungar B., Ozakkafl F., Capan N. Examination of Rotavirus and Enteric Adenovirus in Children with Acute Gastroenteritis. T rk Mikrobiyol. Cem. Derg., 2006; 36(4): 210-3.

24. Huh J.W., Kim W.H., Moon S.G., Lee J.B., Lim Y.H. Viral etiology and incidence associated with acute gastroenteritis in a 5-year survey in Gyeonggi province, South Korea. J. Clin. Virol., 2009; 44(2): 152-6.

25. Hamkar R., Yahyapour Y., Noroozi M., Nourijelyani K, Jalilvand S, Adibi L, et al. Prevalence of Rotavirus, Adenovirus, and Astrovirus Infections among Patients with Acute Gastroenteritis in, Northern Iran. Iran J Public Health., 2010; 39(2): 45-51.

26. Farkas T, Jiang XI: Rotaviruses, Caliciviruses, Astroviruses, Enteric adenoviruses and Other Diarrheic Viruses. In Manual of Clinical Micriobiology 9th edition. Edited by: Murray PR, Baron EJ, Jorgensen JH, Landry ML, Pfaller MA. Washington DC: ASM Press; 2007: 1453-69.

27. Kim J, Kim HS, Kim JS, Song W,Lee KM, Lee $S$ et al. Evaluation of an Immunochromatographic Assay for the Rapid and Simultaneous Detection of Rotavirus and Adenovirus in Stool Samples. Ann. Lab. Med., 2014; 34: 216-222. 